
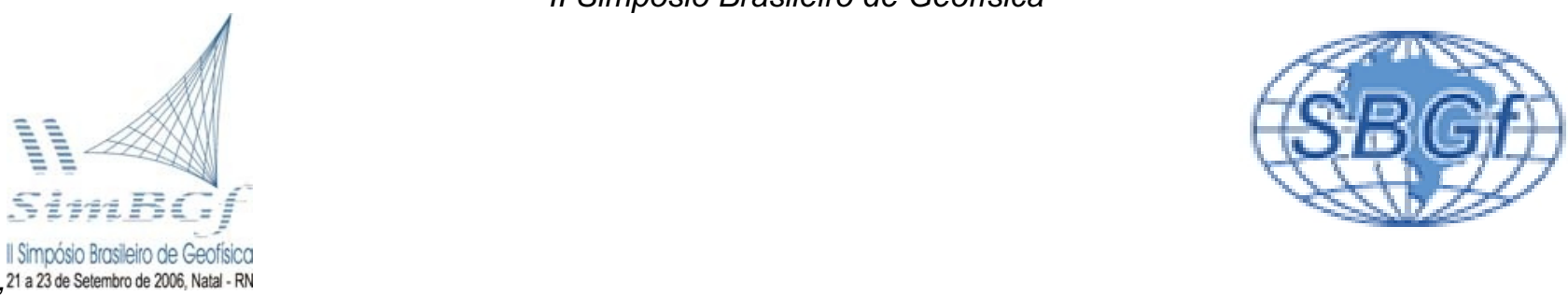

\title{
Prospecção Geofísica de Água Subterrânea - Métodos de Eletrorresistividade e VLF (Very Low Frequency) - em Terrenos Cristalinos nas Aldeias de Etnia Pankará, Município de Carnaubeira da Penha-PE
}

Irabson Mota Cavalcante, Prospectus Nordeste Ltda

Raimundo Mariano Gomes Castelo Branco, DEGEO-UFC

Enéas Oliveira Lousada, DEGEO-UFC

José Nirton da Silva Júnior, DEGEO-UFC

Helena Porto Lira, FUNASA-PE

Este texto foi preparado para a apresentação no I/ Simpósio de Geofísica da Sociedade Brasileira de Geofísica, Natal, 21-23 de setembro de 2006. Seu conteúdo foi revisado pela Comissão Tecno-científica do I/ SR-SBGf mas não necessariamente representa a opinião da SBGf ou de seus associados. E proibida a reprodução total ou parcial deste material para propósitos comerciais sem prévia autorização da SBGf.

\section{Resumo}

Este trabalho compreende os estudos de hidrogeologia utilizando os métodos geofísicos de Eletrorresistividade e VLF para locação de poços tubulares profundos em terrenos de rochas cristalinas nas Aldeias Brejinho, Boqueirão, Olho D’água dos Muniz / São Bento e Vila / Lagoa, de Etnia Pankará, Município de Carnaubeira da Penha-PE. Foi utilizado o arranjo Schlumberger para os perfis elétricos de resistividade (PER) em áreas alvos determinados na fotointerpretação prévia quando se identificou zonas fissurais. Os trechos de queda de resistividade aparente foram corroborados com perfis VLF paralelos. Os métodos geofísicos utilizados se mostraram plenamente aplicáveis para o ambiente geológico da região estudada a qual situa-se no sertão do estado de Pernambuco.

\section{Introdução}

As Aldeias Olho D'água dos Muniz / São Bento, Boqueirão, Lagoa / Vila e Brejinho localizam-se na Serra do Arapuá, no território indígena de etnia Pankará, município de Carnaubeira da Penha-PE (figura 01). Cartograficamente situam-se na porção sul da Folha Mirandiba (SC.24-X-A-I). O Acesso à área, a partir de Recife, é realizado pela rodovia BR-232 até a entrada para cidade de Mirandiba, a partir de onde o acesso se faz pela rodovia PE-423, a qual é pavimentada até esta cidade, e sem pavimentacão até a cidade de Carnaubeira da Penha, percorrendo-se cerca de $490 \mathrm{~km}$ no total. Para Serra do Arapuá percorre-se mais $15 \mathrm{~km}$ para sul em estrada secundária carroçável.

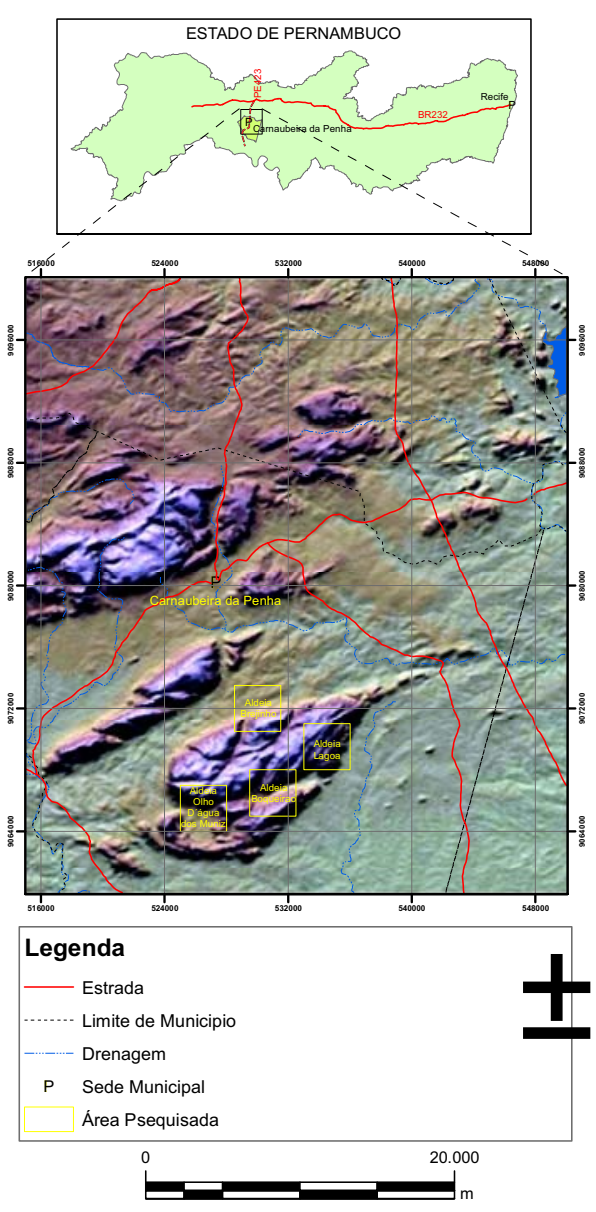

Figura 01 - Mapa de localização e acesso às áreas das Aldeias Brejinho, Olho D’água dos Muniz, Boqueirão e Vila, município de Carnaubeira da Penha - PE 
Em avaliação regional a geologia da Serra do Arapuá, onde estão inseridas as Aldeias alvo dos serviços, ocorrem rochas do ambasamento cristalino pertencente ao amplo contexto da Província Borborema (Almeida, 1977) nos terrenos do Domínio da Zona Transversal do Alto Pajeú (Gomes, 2001) e é caracterizada por unidades neoproterozóicas constituídas por rochas graníticas os quais sobressaem-se topograficamente em relação a encaixante mesoproterozóica, de relevo mais arrasado, associado as rochas do Complexo São Caetano. Esta feição morfológica marca o contato abrupto entre estas duas unidades. O emplacement deste corpo tem um nítido controle estrutural que resultou numa forma de gota ao batólito granítico com eixo ENE. Em termos da geologia estrutural, a área pesquisada foi atingida por diversos ciclos tectônicos variando desde a fase dúctil, marcada principalmente pelas foliações das encaixantes e lineação mineral destas e dos granitos, à fase rúptil evidenciada pelas estruturas planares (falhas e fraturas) penetrativas ao corpo ígneo e sua encaixante, as quais se constituem como de interesse hidrogeológico por servirem de aqüíferos fissurais os quais se condicionam como o único meio passível de aproveitamento hídrico neste tipo de ambiente.

O uso de "ferramentas" geofísicas para detecção destes aqüíferos vem sendo utilizado com freqüência nas últimas décadas no Semi-árido de rochas cristalinas dos estados nordestinos, principalmente Ceará, Pernambuco e Bahia, se justificando pelo ganho significativo das vazões dos poços nesta região através de prospecção geofísica. Com finalidade de se determinar locais com potencial para a captação de água subterrânea através da construção de poços tubulares profundos produtivos para abastecimento comunitário dessas aldeias, a FUNASA - Coordenação Regional de Pernambuco contratou os serviços de empresa especializada em Hidrogeologia e Geofísica com objetivo de se aplicar os métodos geofísicos de Eletrorresistividade e VLF (very low frequency) à prospecção de água subterrânea.

\section{Metodologia}

Em suma, o problema investigado do estudo geofísico foi identificar zonas anômalas, detectáveis pelos métodos geofísicos de Eletrorresistividade e EMVLF, associadas às estruturas que sirvam de circulação e armazenamento de água em ambiente cristalino nas áreas alvos pré-selecionadas na etapa de Fotointerpretação.

A metodologia adotada constou de várias etapas de gabinete e campo detalhadas a seguir:

-•Pesquisa bibliográfica e levantamento de dados técnicos de poços tubulares existentes na região circunvizinha;

- Utilização de mapa planialtimétrico (escala 1:100.000) Folha Mirandiba (SC-24-X-A-I), mapa geológico da Folha Belém de São Francisco (escala de 1:250.000), mapa geológico do Estado do Pernambuco (escala 1:500.000), mapa geológico da Folha Aracaju (escala 1:1.000.000) e fotografias aéreas (escala de 1:25.000);
- Uso de equipamento GPS para localização precisa das estruturas previamente identificadas e amarração dos pontos prospectados;

- Levantamento de campo, identificação dos litotipos e atitudes das estruturas geológicas locais;

- Utilização do método geofísico VLF (Very Low Frequency) para investigações de estruturas planares em domínio cristalino. O princípio deste método eletromagnético de prospecção baseia-se, basicamente, em uma fonte, na qual circula uma corrente alternada que cria um campo indutivo alternado, chamado campo eletromagnético indutivo primário (o campo primário). A extensão da distribuição, na qual o campo primário pode fazer sentir a sua ação, depende da intensidade da corrente primária. Se no raio de ação do campo primário existir um corpo condutor (corpo com condutividade contrastante em relação ao meio no qual se encontra instalado), terá nele induzida uma corrente, chamada de corrente secundária. Havendo portanto uma corrente secundária induzida circulando no corpo condutor, esta corrente, por sua vez, cria também um novo campo eletromagnético indutivo (o campo secundário). Se no raio de ação destes dois campos estiver instalada uma bobina, ela terá nela induzida uma corrente que será a soma (campo total) da ação do campo primário mais a ação do campo secundário induzido no corpo condutor, em função da sua intensidade, freqüência e fase desses campos. Trata-se assim de uma metodologia, onde em geral, a corrente primária circula através de uma bobina e a investigação do campo total (resultante) também se faz através de uma bobina (figura 02). Este procedimento é em geral de execução relativamente fácil e rápida no campo através de aparelho receptor de ondas de freqüência muito baixa. O equipamento receptor utilizado foi o WADI da empresa sueca ABEM e as estações emissoras sintonizadas no trabalho foram a $24,0 \mathrm{kHz}$ e $21,7 \mathrm{kHz}$; realizou-se perfis com distancia entre estações de leitura de 10 e $5 \mathrm{~m}$

- Utilização do método geofísico elétrico para investigações de estruturas planares em ambiente cristalino (Perfis Elétricos de Resistividade). O equipamento utilizado para medições de campo foi um eletrorresistivímetro marca PER-80 fabricado pela DPM Engenharia. Também foram utilizados bobinas de fiação flexível $1,5 \mathrm{~mm} 2$, eletrodos $A-B$ de aço inoxidável maciço e eletrodos $\mathrm{M}-\mathrm{N}$ de cobre maciço e bateria (12V) como fonte de carga elétrica. Um Lap-Top tipo Pentium - 100 $\mathrm{MHz}$ serviu para cálculo das resistividades aparentes e construção das curvas em tempo real, o que permitiu o acompanhamento e entendimento das variações das resistividades e retificações e/ou ratificações de leituras; realizou-se perfis com arranjo Schlumberger com distância entre estações de 10 e 20m

- Interpretação final dos dados geofísicos para determinação do melhor ponto para a perfuração, elaboração dos mapas temáticos e emissão do relatório final com dados e análises do trabalho de prospecção realizado. 


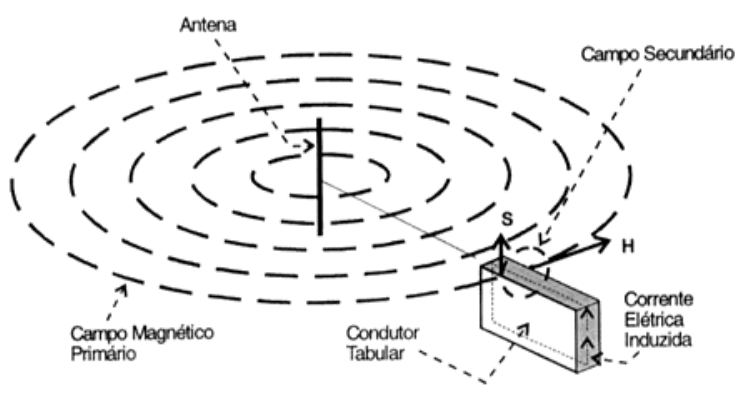

Figura 02 - Origem e propagação do campo eletromagnético primário e secundário VLF (Phillips \& Richards 1975, in: Feitosa 1997).

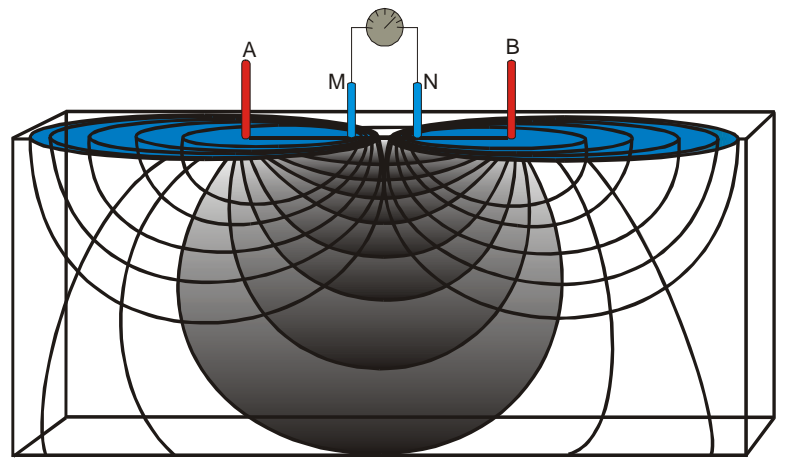

Figura 03 - Arranjo Schlumberger e a relação entre as linhas de corrente e as superfícies eqüipotenciais. A e B representam os eletrodos de injeção de corrente elétrica; $\mathrm{M}$ e $\mathrm{N}$ representam os eletrodos de medida do potencial (Cunha, 2002).

\section{Resultados}

\section{PERFÍS ELÉTRICOS}

Os Perfis Elétricos de Resistividade (PER) foram posicionados interceptando perpendicularmente os traços de fratura previamente identificados nas fotografias aéreas. As aberturas dos eletrodos de corrente foram determinadas de acordo com as profundidades a serem investigadas, proporcionando contraste compatível para os valores de resistividade aparente e curvas passíveis de interpretação.

As curvas resultantes da aplicação da pesquisa geofísica pelo método de Perfis Elétricos de Resistividade foram tratadas com auxílio do programa EXCEL, in loco, no qual os dados da resistividade aparente obtida foram plotados ao longo do perfil executado, considerando-se as estações de leitura e seus espaçamentos (figura 04)

Realizou-se de 4 a 5 Perfis Elétricos em cada Aldeia. As orientações não seguiram um padrão uniforme em virtude das diferenças de atitudes das fraturas identificadas nas áreas, sendo, a maioria, executados na direção NE-SW, posicionado o mais perpendicular possível às fraturas alvo. $O$ arranjo utilizado foi Schlumberger com abertura dos eletrodos de corrente -
$A B$ - variando de 80 a $160 m$ e de recepção - MN - de $20 \mathrm{~m}$

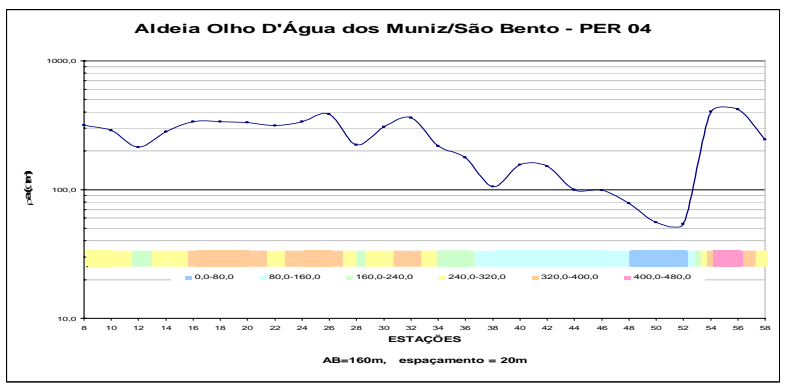

Figura 04 - Curva de resistividade aparente em escala logarítmica para uma profundidade teórica de investigação de cerca de 40m

A figura 08 mostra os perfis que representaram os melhores resultados, cujos valores de resistividade aparente mais baixos são da ordem de 100-200 ohm.m, os quais foram confirmados com o perfil VLF e subsidiaram a decisão para as locações dos poços.

\section{PERFÍS VLF}

O método VLF foi aplicado para agregar e corroborar as informações obtidas pelos caminhamentos elétricos.

Realizou-se perfis VLF coincidentes aos dos caminhamentos elétricos executados. A seleção dos perfis VLF realizados teve como base a curva resultante de resistividade aparente do perfil elétrico, considerando os trechos de anomalia negativa dos valores da resistividade obtidos associados às estruturas fotointerpretadas.

A maioria dos perfis VLF confirmou a existência de zonas anômalas nos pontos de queda de resistividade do Caminhamento Elétrico, equivalendo-se a esta metodologia, entretanto, em locais com existência de materiais condutivos (redes elétricas, cercas, etc) o resultado da aplicação do método VLF fica comprometido por interferência destas estruturas.

Foram realizados os perfis VLF indo e voltando no mesmo trecho em todos os perfis, com distância entre estações de 10 e $5 \mathrm{~m}$, respectivamente. Vale ressaltar que os resultados deste procedimento foram redundantes e não se verificou incremento de informação, como ilustram as figuras abaixo 05, 06 e 07.

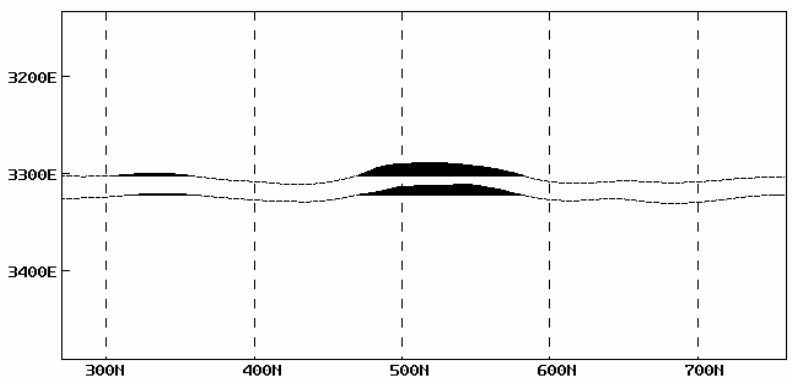

Figura 05 - Curvas integradas de dados filtrados de perfil VLF (real) para uma profundidade de 30m (distância entre estações de 10 e 5m) - Aldeia Boqueirão 

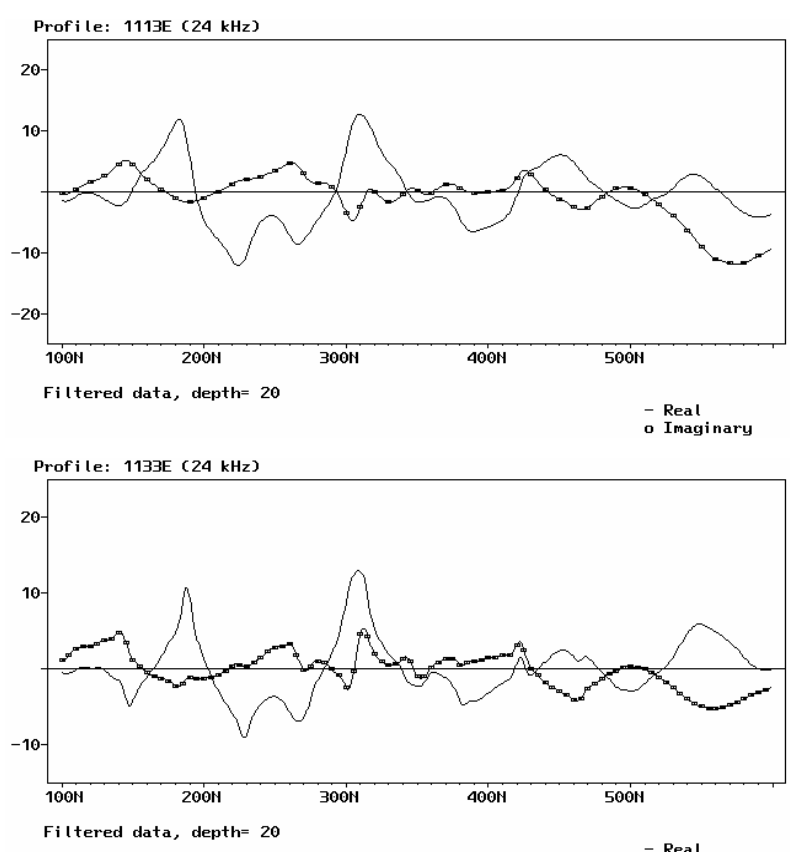

- Real

Figura 06 - Curvas de dados filtrados de perfil VLF de densidade de corrente equivalente (real) e de condutividade (imaginária) para uma profundidade de 20m (distância entre estações de 10 e 5m) - Aldeia Brejinho

Profile: 2203Ernaubeira da Penha-0lho Dagua dos Muni z-FUHASA

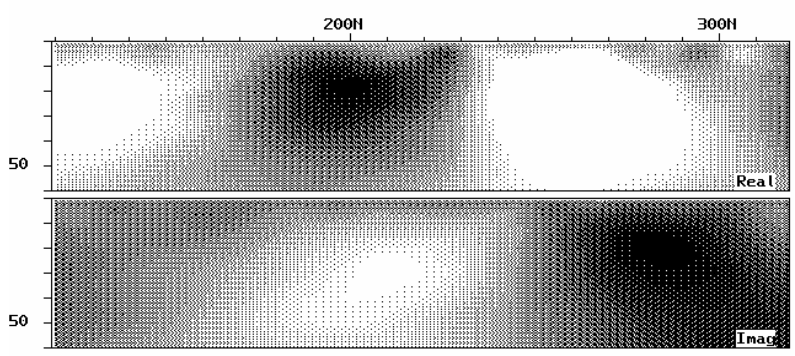

Profile: 2223Ernaubeira da Penha-0lho Dagua dos Muniz-FUHASA

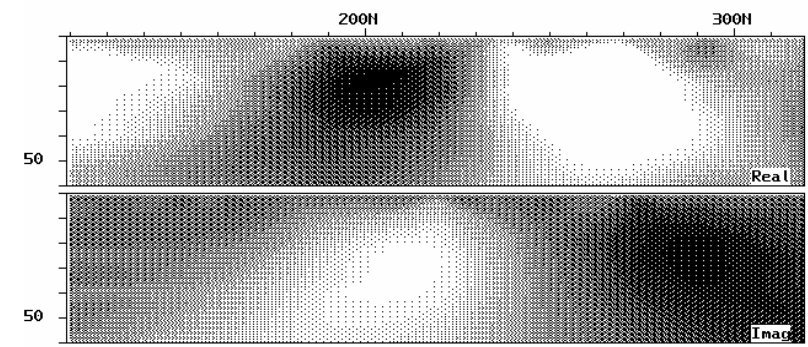

Figura 07 - Anomalias de ondas VLF em seção transversal vertical (real e imaginária) (distância entre estações de 10 e 5m) - Aldeia Olho D'Água dos Muniz

\section{Conclusões}

Os critérios para locação dos poços foram as respostas integradas dos dois métodos utilizados (VLF e Eletrorresistividade). A hierarquização dos pontos para perfuração dos poços tubulares considerou a análise das fotografias aéreas, as quais serviram de base para seleção dos pontos alvos para investigação geofísica, e os resultados dos métodos geofísicos aplicados, procurando integrar as anomalias geradas nos perfis VLF e os pontos de queda da resistividade aparente evidente nos Perfis Elétricos de Resistividade.

A pesquisa realizada confirma a assertiva de que a integração destas metodologias geofísicas representa o melhor procedimento de investigação indireta para prospecção de água subterrânea em ambiente cristalino tanto no que refere aos critérios técnicos quanto à análise de custo/benefício, no entanto, vale salientar que não tem como se estimar vazão e qualidade de água.

\section{Agradecimentos}

Agradecemos a FUNASA - Coordenação de Pernambuco - e ao Laboratório de Geofísica de Prospecção e Sensoreamento Remoto do Departamento de Geologia da UFC

\section{Referências Bibliográficas}

CAVALCANTE, I. M. Hidrogeologia, hidroquímica e geofísica (método VLF) de aqüíferos fissurais em uma porção da folha Garanhuns, Agreste Meridional do Estado de Pernambuco. Universidade Federal do Ceará, Departamento de Geologia. Dissertação de Mestrado, 2000. 117p.; il.

CUNHA, L. S. Prospecção de água suterrânea em terrenos sedimentares na região litorânea cearense (cascavel-ce): integração de dados geofísicos, hidrogeológicos e hidroquímicos. Dissertação de Mestrado em Geologia - Universidade Federal do Ceará, 2002.

FEITOSA, E. C. Pesquisa de água subterrânea, 1997. In: Feitosa, F. A. C. \& Manoel Filho, J. Hidrogeologia: Conceitos e Aplicações, 1997. CPRM. Cap. 4. p. 53 80.

GOMES, H. A. Programa Levantamentos Geológicos Básicos do Brasil. Serra Talhada. Folha SC.24-Z-C. Estado de Pernambuco, Paraíba e Ceará. Escala 1:250.000. Geologia e metalogênese. Brasília: CPRM, 1999.

GOMES, H. A. Geologia e recursos minerais do estado do Pernambuco. Brasília: CPRM / DIEDIG / DEPAT, 2001. 198p.; il.; mapas; escala 1:500.000.

SANTOS, E. J. [CD ROM] Programa Levantamentos Geológicos Básicos do Brasil. Belém do São Francisco. Folha SC.24-X-A. Estado de Pernambuco, Alagoas e Bahia. Escala 1:250.000. Geologia e metalogênese. Recife: CPRM, 2000. Disponível em 1CD.

SUDENE, SC.24-X-A-I - Folha Mirandiba. Departamento de Recursos Naturais - Divisão de Cartografia. 1972. $2^{\mathrm{a}} \mathrm{Ed}$. 
Figura 08 - Prancha com integração das curvas de resistividade aparente (PER) e das curvas de dados filtrados de perfil VLF de densidade de corrente equivalente (real) e de condutividade (imaginária); Anomalias onde foram marcados os pontos para perfuração dos poços tubulares profundos.
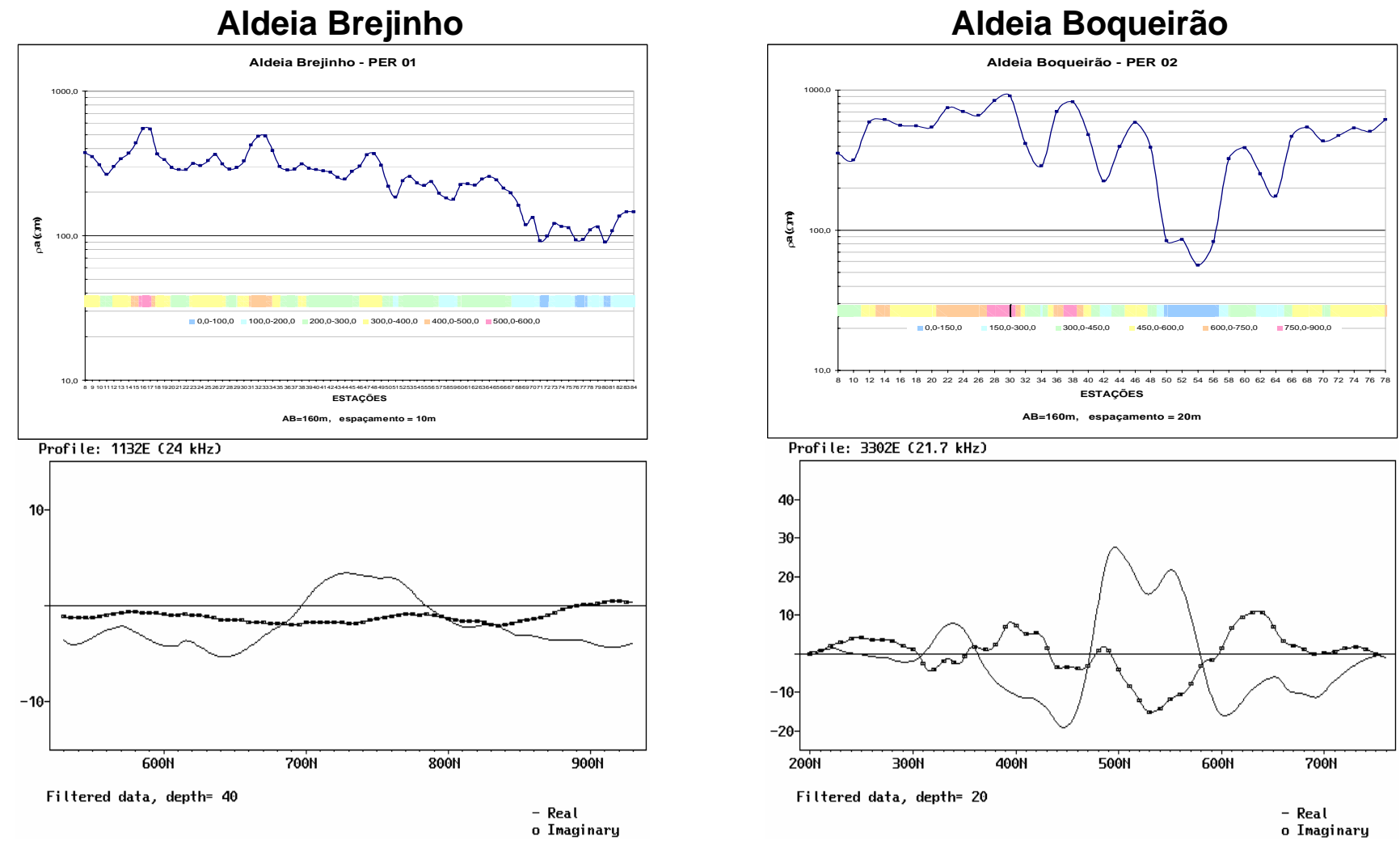

Aldeia Olho D' Água dos Muniz
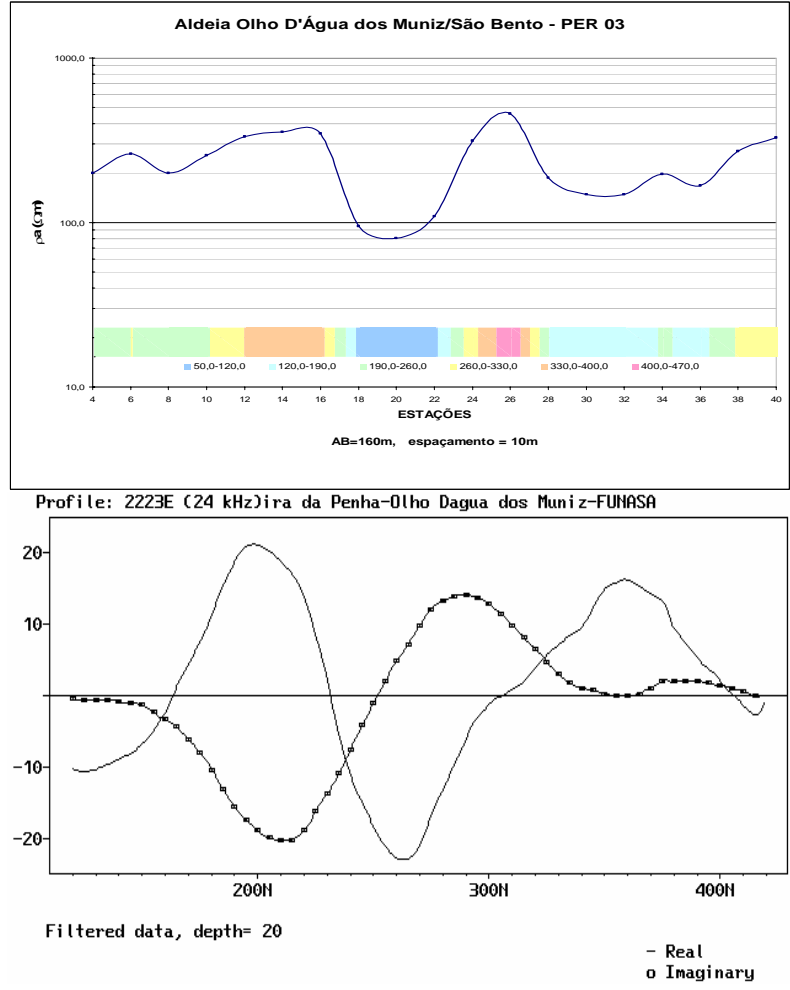

Aldeia Vila
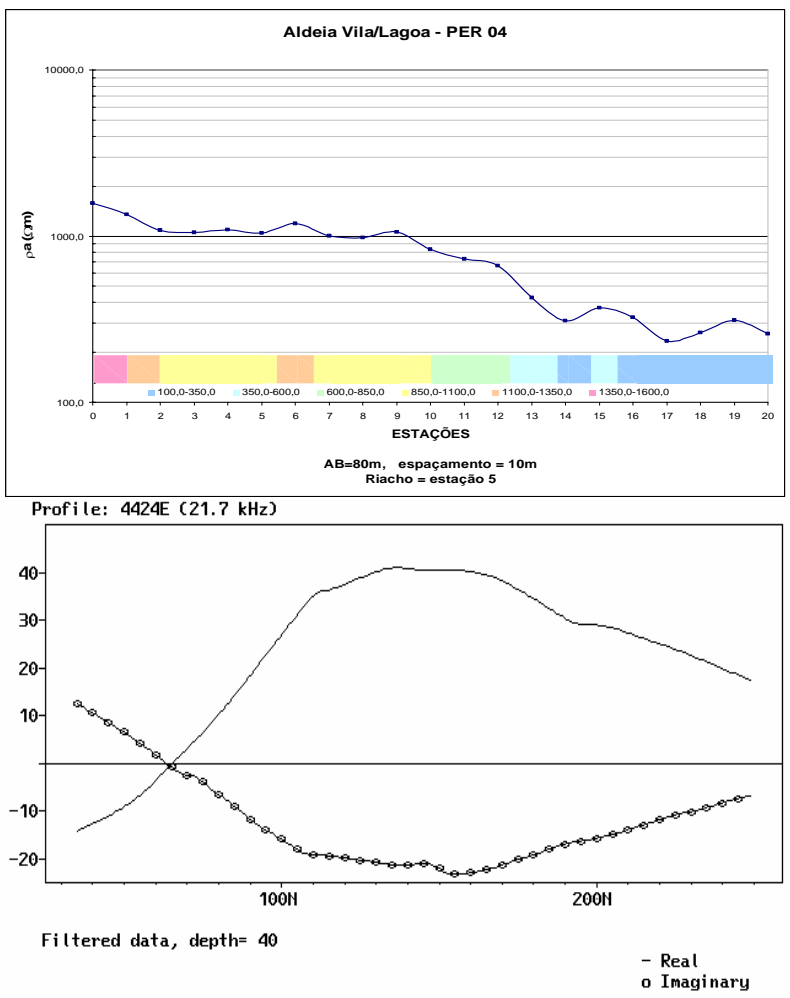